\title{
Anxiety and Depression among new entrants in a Medical College
}

\section{Vikrant Prabhakar ${ }^{1}$, Amrit Virk ${ }^{2}$, Parmal Saini ${ }^{3}$}

${ }^{1}$ Associate Professor, Department of Community Medicine, Adesh Medical College, Kurukshetra; ${ }^{2}$ Professor, Department of Community Medicine, Adesh Medical College, Kurukshetra; ${ }^{3}$ Assistant Professor, Department of Community Medicine, Adesh Medical College, Kurukshetra

\begin{tabular}{|c|c|c|c|c|c|c|c|}
\hline Abstract & Introduction & Methodology & Results & Conclusion & References & Citation & Tables / Figures \\
\hline \multicolumn{8}{|c|}{ Corresponding Author } \\
\hline \multicolumn{8}{|c|}{$\begin{array}{l}\text { Dr. Parmal Saini, Ph.D, Assistant Professor, Department of Community Medicine, Adesh Medical College, } \\
\text { Kurukshetra, Haryana } \\
\text { E Mail ID: sainiparmal@gmail.com }\end{array}$} \\
\hline
\end{tabular}

\section{Citation}

Prabhakar V, Virk A, Saini P. Anxiety and Depression among new entrants in a Medical College. Indian J Comm Health. 2020;32(1):57-61.

Source of Funding: Nil Conflict of Interest: None declared

\section{Article Cycle}

Received: 15/11/2019; Revision: 15/01/2020; Accepted: 08/02/2020; Published: 31/03/2020 This work is licensed under a Creative Commons Attribution 4.0 International License.

\section{Abstract}

Background: Depression is commonly reported by university students due to change in environment, academic demands, developing new relations and more financial freedom. If that professional course happens to be medical education, the transition is even more drastic. Studies have also shown that Quality of Life $(\mathrm{QOL})$ is negatively affected by the presence of anxiety and depression. Aim: Present study aims to find the prevalence of anxiety, depression and stress among students who have recently joined medical college. Materials \& Method: This cross-sectional study was undertaken at Private medical college in north India. Depression, Anxiety and Stress Scale (DASS) was used for the data collection. MBBS students who have joined the institution in August 2019 were included in the study. Statistical Analysis Used: Data was entered in excel and analysed using Statistical Package for Social Science (SPSS) Version 21. Result: We found that almost half of the students who participated in the study had scores above 10 (meaning thereby depressed) on the depression scale, with $23.5 \%$ of respondents showing moderate or severe depression. Two-third students experienced anxiety, with $20 \%$ students having severe to very severe anxiety. Stress levels amongst the students were also high, with $47 \%$ of the students reporting stress. $3.4 \%$ students experienced severe or very severe stress. Conclusion: Medical students have high prevalence of stress, anxiety and depression. It is recommended that medical colleges should implement appropriate and timely measures to address students' well-being and offer comprehensive intervention and preventive programs to help students cope with this transition phase.

\section{Keywords}

\section{Stress; Depression; Medical Students}

\section{Introduction}

Depression and anxiety are a significant public health problem. Depression is the fourth most important contributor to the global burden of the disease and $4.4 \%$ of the total disability adjusted life years (DAILY) is explained by depression $(1,2)$. Anxiety is a vague feeling of apprehension, worry, uneasiness or dread, the source of which is often non-specific or unknown to the individual (3), whereas a depressed patient feels sad, has low energy and loses all interest in day-to-day activities. Though the features are not different from normal mood changes, the differentiation is made on the basis of severity of symptoms and duration of the disorder (4). The transition from school education to professional college is a major turning point for a young adult, causing mal-adjustments. Depression is commonly reported by university students $(5,6)$ due to change in environment, academic demands, developing new relations and more financial freedom (7). If that professional course happens to be medical education, the transition is even more drastic (8). Medical college environment and the demands of medical education cause greater degree of depression as compared to engineering students (9), given the fact that Medical Colleges are known to be stressful environment for students (10), because of long working hours, lack of sleep, fear of failure, lack of peer support and exposure to 

practical education sessions very different from those experienced in the school classrooms. Medical students report higher prevalence of mental health problems compared to other professional course students $(11,12)$, due to prevailing education system (13). Studies have shown high prevalence of depression of $20-30 \%$ among medical students $(14,15)$. In Malaysia, $44 \%$ and $34.9 \%$ of medical students attending a private university have been reported to have some levels of anxiety and depression (16). Studies have also shown that Quality of Life (QOL) is negatively affected by the presence of anxiety and depression $(17,18,19)$. Medical students have consistently shown lower QOL as compared to peers $(20,21)$. However, not many students seek help for the problems (22), because of varied fears.

\section{Aims \& Objectives}

To find Present study aims a cross sectional study to find the prevalence of anxiety, depression and stress among students who have recently joined medical college.

\section{Material \& Methods}

This cross-sectional study was undertaken in October 2019. The study was approved by the Institutional Ethical Committee. Depression, Anxiety and Stress Scale (DASS) was used for the data collection. DASS is a set of three selfreported scales, measuring depression, anxiety and stress respectively. Each section has fourteen questions and the response are graded between 0 (does not apply to me) to 3 (apply to me very much most of the time). MBBS students who have joined the institution in August 2019 were included in the study. The students were asked to respond to the questions in a self-reported, anonymous fashion in a single session, after obtaining an informed verbal consent. It was decided that students who decline to participate in the survey will be excluded from the study. Students absent on the day of data collection were also excluded from the study population.

The total score of each section is than classified as given in (Table 1) (23)

Data collected was entered into Microsoft Excel sheet. Descriptive statistics were calculated for Depression, Anxiety and Stress. Percentages and number of participants are presented for categorical data. Karl Pearson's coefficient of correlation was used to study the correlation between Depression, Anxiety and Stress. $P$ value $<0.05 \quad(<0.01)$ was considered as statistically significant (Highly significant). Statistical analysis was performed using SPSS version 21.

\section{Results}

A total of 150 first year students were eligible to participate in the study. However, on the day the data collection, a total of 115 students, present and agreed to participate in the study, were included in the study.
We found that almost half of the students who participated in the study had scores above 10 (meaning thereby depressed) on the depression scale, with $23.5 \%$ of respondents showing moderate or severe depression. A total of 60 students (52.2\%) had score less than 10 (normal). (Table 2)

Two-third students experienced anxiety, with $20 \%$ students having severe to very severe anxiety. $14.8 \%$ were classified under mild anxiety category, and $27.8 \%$ had scores corresponding to moderate anxiety category. (Table 3)

Stress levels amongst the students were also high, with $47 \%$ of the students reporting various levels of stress. Of these, 3.4\% students experienced severe or very severe stress. $53 \%$ students reported no stress. (Table 4)

The three DASS scales were all moderately inter-related, with value of $r$ varying between 0.5 to 0.7 . (Table 5 )

\section{Discussion}

Various studies have confirmed the high prevalence of stress, anxiety and depression among medical students. Though there have been wide variations in the prevalence of depression reported ( $9 \%$ to $56 \%$ ), meta-analysis of 167 cross sectional studies for 43 countries reported depression prevalence of $27.2 \%$ (14). Similar figures (28\%) were also obtained in another meta-analysis of 77 studies $(12,24)$. However, much higher rates, as high as $58 \%(5)$ have been reported from studies conducted in India. Other studies have also shown high prevalence, $51.3 \%$ from Odisha (22) and 45.4\% from Andhra Pradesh (24). In a similar study, depression was found in $28.7 \%$ of the students (10). In the study in Ethiopia, magnitude of anxiety was $30.1 \%(25)$, which was similar to studies in Brazil (33.7\%) (26). However, low rates were reported from India (9.8\%) (27) and Nepal (5\%) (28) whereas it was reported at 73\% in Egypt (29), 51\% in Bahrein (30), 70.7\% in Pakistan (31).

A systematic review of 29 studies from North America reported the Prevalence of 7.7-65.5\% for anxiety, 12.2$96.7 \%$ for psychological distress (32). A meta-analysis of 59 studies from Brazilian medical students reports the prevalence of anxiety among $32.9 \%$ and stress among $49.9 \%$ (33). A discreet study from Nepal reported an overall prevalence of anxiety in $41.1 \%$ and stress in $27 \%$ of Nepalese medical undergraduates (34). Indian studies have reported the prevalence of anxiety and stress among $66.9 \%$ and $53 \%(22), 64.9 \%$ and $40 \%$ (24), 50.6\% and $32.8 \%$ respectively (35).

First year medical students have been found to be 12.06 times more likely to have anxiety as compared to final year students (25). Similar results have been reported from studies in Pakistan (13). Low levels (20.28\%) of stress were reported among final year students of Deccan medical college Hyderabad indicating better stress management 
strategies by students like regular sports, peer support and active participation of teachers in student counselling (10).

Moutinho et al reported marked differences in prevalence of depression and anxiety among medical students from different course semesters. Indian studies showed high prevalence of depression and anxiety among second term students when compared to eight term medical students. As stated by Mandal et al the reasons for stress among second term students may be language problem, vast syllabus, fear of failure, parental and peer pressure, tight schedule, away from home, tough topics, substance abuse etc $(35,36)$.

\section{Conclusion}

The study confirms the high prevalence of psychological mal adjustments in medical students. High prevalence of stress, anxiety and depression highlights the importance of developing strategies to identify students at risk of developing mental stress and disorders, and institute comprehensive wellness programs and strategies to improve capacities of the students to cope with the emotional and psychological stress. Mentorship programs (like FAME) will help the students in coping with life and academic stress and will have definite positive impact on mental wellbeing of the medical students.

\section{Recommendation}

There has been an increased interest among the governing body for Medical Education (The Medical Council of India) to look into the welfare of medical students. This study throws light on an important component of wellbeing ie. mental health among medical students. This, and other such studies should be taken as reference to design programs for welfare of medical students so that the future generation of health care professionals are able lead a comprehend the vast medical knowledge in a healthy environment and are also to develop as efficient professionals and are able to provide health care services more efficiently.

\section{Limitation of the study}

One of the limitations of this study was a small sample size, limited to a single college. Additionally, as it was a cross sectional study, we could not comprehensively evaluate psychological symptoms and its progress throughout the course. We have also not taken into consideration students' attitude and interest in the course they have enrolled.

\section{Relevance of the study}

There has been an increase in incidents of violence against doctors. This, coupled with high academic demands and long working hours creates an environment of stress for medical students. It is important that medical colleges take appropriate measures to help students cope with this. An attempt for early identification of risks using tools like DASS and developing programs to help address the stress will go a long way in helping aspiring doctors.

\section{Authors Contribution}

All the authors have contributed significantly for the designing the study, implementing it, collecting data and analyzing data as well as repairing the final document.

\section{References}

1. Sidi $\mathrm{H}$, et al. Depression and the associated factors among elderly hypertensives. Exp Clin Cardiovasc. 2014;20(5):3065-72

2. Michelle FGI. Integrating mental health into primary care: a global perspective. Geneva: WHO; 2008

3. Robert MA, Hirschfeld MD. The comorbidity of major depression and anxiety disorders: recognition and management in primary care. Primary Care Companion J Clin Psychiatry. 2001; 3:6.

4. Marianne C, Kastrup M, Armando Báez Ramos MD. Global mental health. Dan Med Bull. 2007;54: 42-3.

5. Rawat $\mathrm{R}$ et al. Prevalence of depression and its associated factors among medical students of a private medical college in south India Int J Community Med Public Health. 2016 Jun;3(6):1393-1398

6. Diana Sarokhani AD, Yousef V, et al. Prevalence of depression among university students: a systematic review and meta-analysis study. London: Hindawi Publishing Corporation; 2013. p.

7. Aileen M, Pidgeon NFR, Peta S, Heidi BM, Barbara C, Lo Y. Examining characteristics of resilience among University students: an international study. Open J Soc Sci. 2014;2: 14-22.

8. Chenganakkattil $\mathrm{S}$ et al. Comparison of psychological stress, depression and anxiety among medical and engineering students Int J Res Med Sci. 2017 Apr;5(4):1213-1216

9. Naveen S, Swapna M, Jayanthkumar K, Manjunatha S. Stress, anxiety and depression among students of selected medical and engineering colleges, Bangalore-a comparative study. International Journal of Public Mental Health And Neurosciences 2015;2(2):1418.

10. Sayeedunnisa Sarah, Sultan Rizwan Ahmad, A. Chandrasekhar. Prevalence of Anxiety and Depression Among Medical Students Of Deccan Medical College, Hyderabad. Nat J Res Community Med 2018;7(3):229-232.

11. Kumaraswamy N. Academic Stress, Anxiety and Depression among College Students- A Brief Review. International Review of Social Sciences and Humanities, Vol. 5, No. 1 (2013), 135-143

12. Puthran R, Zhang MWB, Tam WM, Ho RC. Prevalence of depression amongst medical students: a meta-analysis. Med Educ 2016; 50: 456-68

13. Sundas Ishtiaq MK, Anum S, Saira M. Prevalence of study related anxiety among female medical students. ISRA Med J. 2013; 5:2.

14. Lisa SR, Marco AR, Matthew T, et al. Prevalence of Depression, Depressive Symptoms, and Suicidal Ideation among Medical Students, A Systematic Review and Meta-Analysis: JAMA. 2016;316(21):2214-2236.

15. DyrbyeLN, Thomas MR, Shanafelt TD. Systematic review of depression, anxiety, and other indicators of psychological distress among US and Canadian medical students. Acad Med. 2006;81(4):354-373

16. Saravanan C, Wilks R Medical students' experience of and reaction to stress: the role of depression and anxiety. Scientific World Journal 2014 doi: 10.1155/2014/737382. eCollection 2014

17. Dyrbye LN, Thomas MR, Massie FS, Power DV, Eacker A, Harper W, et al. Burnout and suicidal ideation among US medical students. Ann Intern Med 2008; 149: 334-41.

18. Olantuji BO, Cisler JM, Tolin DF. Quality of life in anxiety disorders: A meta-analytic review. Clin Psycho Rev 2007; 27: 572-81.

19. Brown LF, Kroenke K, Theobald DE, Wu J, Tu W. The association of depression and anxiety with health-related quality of life in cancer patients with depression and/or pain. Psychooncology 2010; 19(7): 734-41. 
INDIAN JOURNAL OF COMMUNITY HEALTH / VOL 32 / ISSUE NO 01 / JAN - MAR 2020

20. Rapaport MH. Clary C, Fayyad R, Endicott J. Quality of life impairment in depressive and anxiety disorders. Am J Psychiatry 2005; 162: 1171-8.

21. Henning MA, Krägeloh CU, Hawken SJ, Zhao Y, Doherty I. The quality of life of medical students studying in New Zealand: A comparison with nonmedical students and a general population reference group. Teach Learn Med 2012; 24(4): 334-40.

22. Iqbal S, Gupta S, Venkatarao E. Stress, anxiety \& depression among medical undergraduate students \& their socio-demographic correlates. Indian J Med Res. 2015 Mar; 141(3): 354-357.

23. Lovibond, S.H. \&Lovibond, P.F. (1995). Manual for the Depression Anxiety \& Stress Scale (2nd Ed.) Sydney: Psychology Foundation.

24. SujathaPeethala, SrideviGarapati and Appala Naidu Sambangi Assessment of depression, anxiety and stress among undergraduate medical students in Rangaraya Medical College, Kakinada, Andhra Pradesh International Journal of Current Research 9, (09), 58157-58160

25. Kebede, M.A., Anbessie, B. \& Ayano, G. Prevalence and predictors of depression and anxiety among medical students in Addis Ababa, Ethiopia. Int J Ment Health Syst 13, 30 (2019) doi:10.1186/s13033019-0287-6

26. Edméa Fontes de Oliva Costa MVR, Ana Teresa Rodrigues de Abreu $\mathrm{S}$, et al. Common mental disorders and associated factors among final-year healthcare students. Rev Assoc Med Brasil. 2014;60(6):525-30.

27. Suresh C. Prevalence and associated factors of depression, anxiety and stress among undergraduate medical students. Int J Indian Psychol. 2016;3(4):2348-5396.
[Prevalence of Anxiety...] | Prabhakar V et al

28. Adhikari A, Dutta A, Sapkota S, Chapagain A, Aryal A, Pradhan A. Prevalence of poor mental health among medical students in Nepal: a cross-sectional study. BMC Med Educ. 2017;17(1):232.

29. Fawzy M, Hamed SA. Prevalence of psychological stress, depression and anxiety among medical students in Egypt. Psychiatry Res. 2017; 255:186-94.

30. Mahroon ZA, Borgan SM, Kamel C, Maddison W, Royston M, Donnellan C. Factors associated with depression and anxiety symptoms among medical students in Bahrain. Acad Psychiatry. 2018;42(1):31-40.

31. Muhammad S, Khan S, Areef B, Syed UA. Prevalence of depression, anxiety and their associated factors among medical students in Karachi, Pakistan. J Pak Med Assoc. 2006; 56:12.

32. Hope $\mathrm{V}$, Henderson M. Medical student depression, anxiety and distress outside North America: a systematic review. Med Educ. 2014 Oct;48(10):963-79.

33. Pacheco JP, Giacomin HT, Tam WW. Mental health problems among medical students in Brazil: a systematic review and metaanalysis. Rev Bras Psiquiatr. 2017 OctDec;39(4):369-378.

34. Kunwar D, Risal A, Koirala S. Study of depression, anxiety and stress among the medical students in two medical colleges of nepal. Kathmandu Univ Med J 2016;53(1):22-6.

35. Kumar SD et al.Depression, anxiety and stress levels among medical students in Mysore, Karnataka, India Int J Community Med Public Health. 2016 Jan;3(1):359-362

36. Mandal A, Ghosh A, Sengupta G, Bera T, Das N, Mukherjee S. Factors affecting the performance of undergraduate medical students: A perspective. Indian Journal of Community Medicine. 2012;37(2):126-9.

\section{Tables}

\begin{tabular}{|l|l|l|l|}
\hline TABLE 1 DASS CLASSIFICATION OF DEPRESSION, ANXIETY AND STRESS & & Stress \\
\hline $\begin{array}{l}\text { Grading } \\
\text { Normal }\end{array}$ & Depression & Anxiety & $0-14$ \\
\hline Mild & $0-9$ & $0-7$ & $15-18$ \\
\hline Moderate & $10-13$ & $8-9$ & $19-25$ \\
\hline Severe & $14-20$ & $10-14$ & $26-33$ \\
\hline Extremely severe & $21-27$ & $15-19$ & $34+$ \\
\hline
\end{tabular}

TABLE 2 PREVALENCE OF DEPRESSION AMONG THE STUDENTS

\begin{tabular}{|l|c|c|}
\hline Depression Grading with respect to DASS & No of Students & Percentage \\
\hline Normal & 60 & 52.2 \\
\hline Mild Depression & 23 & 20.0 \\
\hline Moderate Depression & 21 & 18.3 \\
\hline Severe Depression & 6 & 5.2 \\
\hline Extremely Severe Depression & 5 & 4.3 \\
\hline Total & 115 & 100.0 \\
\hline
\end{tabular}

TABLE 3 PREVALENCE OF ANXIETY AMONG THE STUDENTS

\begin{tabular}{|l|c|c|}
\hline Anxiety Grading with respect to DASS & No of Students & Percentage \\
\hline Normal & 43 & 37.4 \\
\hline Mild Anxiety & 17 & 14.8 \\
\hline Moderate Anxiety & 32 & 27.8 \\
\hline Severe Anxiety & 13 & 11.3 \\
\hline Extremely Severe Anxiety & 10 & 8.7 \\
\hline Total & 115 & 100.0 \\
\hline
\end{tabular}

TABLE 4 PREVALENCE OF STRESS AMONG THE STUDENTS Stress Grading with respect to DASS

Normal

Mild Stress

Moderate Stress

Severe Stress

Extremely Severe Stress

Total

No of Students

Percentage

\begin{tabular}{|c|c|}
\hline 61 & Percentage \\
\hline 27 & 53.0 \\
\hline 23 & 23.5 \\
\hline 2 & 20.0 \\
\hline 2 & 1.7 \\
\hline 115 & 1.7 \\
\hline
\end{tabular}


TABLE 5 CORRELATION BETWEEN STRESS, ANXIETY AND DEPRESSION SCORES OF THE STUDY SUBJECTS

\begin{tabular}{|c|c|c|c|c|c|}
\hline & Mean & Std. Deviation & $\mathbf{N}$ & Karl Pearson's Coefficient of Correlation ( $r$ ) & p Value \\
\hline Stress & 13.49 & 7.20 & 115 & \multirow[t]{2}{*}{0.707} & \multirow[t]{2}{*}{$<0.001^{*}$} \\
\hline Anxiety & 10.10 & 6.68 & 115 & & \\
\hline Stress & 13.49 & 7.20 & 115 & \multirow[t]{2}{*}{0.673} & \multirow[t]{2}{*}{$<0.001^{*}$} \\
\hline Depression & 10.39 & 7.92 & 115 & & \\
\hline Anxiety & 10.10 & 6.68 & 115 & \multirow[t]{2}{*}{0.592} & \multirow[t]{2}{*}{$<0.001^{*}$} \\
\hline Depression & 10.39 & 7.92 & 115 & & \\
\hline
\end{tabular}

